\title{
Discursos de las becarias y los becarios en torno al nuevo sistema de becas y ayudas al estudio en la Universidad
} Grant-holder's Discourses in Relation to the New University Financial Aid System

\section{Delia Langa Rosado'}

\section{Resumen}

A partir de 2013 se ha experimentado en España un giro en el sistema de becas universitarias que las ha hecho más competitivas y sujetas al rendimiento académico. Nos hemos acercado a esta temática a través de las experiencias de los propios estudiantes con beca y para ello hemos analizado los discursos producidos por medio de 31 entrevistas abiertas. En este texto nos centraremos en las opiniones y representaciones de los sujetos entrevistados sobre estas transformaciones e intentaremos descifrar el concepto de equidad que manejan. A pesar de los mayores esfuerzos, académicos y económicos, que implica la apuesta universitaria en el actual contexto, sus pareceres sobre la reforma de las becas se muestran escasamente críticos, o bastante ambivalentes. Intentaremos ofrecer alguna interpretación sobre esto en clave de debilitamiento de la concepción de la educación como derecho ciudadano.

\section{Palabras clave}

Estudiantes universitarios, desigualdad, clases sociales, becas, política universitaria.

\section{Abstract}

After 2013 the financial aid university system has moved to a more competitive one and has made grants more dependent on educational achievement. We have approached to this issue through grant-holders'experiences by means of 31 in depth interviews discourses. In this paper we have focused our attention in student's opinions and representations about the reforms. We will try to approach to the sense of equity for them. In spite of the harder academic and financial efforts that involve their university bet in present, student's opinions about grant reform seem not much critical, or very ambivalent. We will try to offer some interpretation of it as a process of weakening of education understood as a civic right.

Keywords

University students, inequality, social class, grants, university politics. 


\section{El nuevo contexto institucional para el estudiantado universitario: renovadas y desiguales exigencias}

Si los niveles educativos preuniversitarios han experimentado en la última década importantes cambios legislativos que han reorganizado el sistema y sus modos de transitar por él, en la Universidad, sin haberse concretado en una nueva ley reguladora, también han tenido lugar una serie de transformaciones de cuyo alcance, así como de la interrelación de las distintas medidas, quizá no seamos tan conscientes. Estas modificaciones sin embargo han configurado un nuevo contexto de acceso y permanencia para los estudiantes, y veremos, han dado lugar a un conjunto de nuevas exigencias que afectan especialmente al alumnado procedente de los sectores sociales populares.

Aunque en este artículo me centraré en el tema de las becas, la reforma de éstas a partir de 2013 no puede dejar de verse en conexión con otros dos importantes procesos. El primero es la adaptación al Espacio Europeo de Educación Superior, que culmina en 2010. La llamada reforma de Bolonia hace desaparecer las diplomaturas, alarga a cuatro los años como mínimo la duración de las titulaciones, en las que se introducen exigencias (mayor presencialidad, acreditación del nivel de idiomas, obligatoriedad de los TFG) que de un modo especial expresan como nuevos obstáculos los estudiantes de clases populares (Langa Rosado, 2018). Los grados, no obstante, lejos de aumentar así su valor, se convierten en camino casi obligado a continuar con algún tipo de formación de postgrado: los cotizados másters, cuyos créditos además pasan a tener unos precios bastante más elevados, lo que también es una importante novedad de Bolonia (Sacristán, 2014).

El segundo proceso al que me refiero tiene que ver con la subida de las tasas universitarias, que si bien se venía dando gradualmente desde unos años antes, llevará con la aplicación del Real Decreto ley 14/2012 a un espectacular crecimiento del ingreso de las universidades del 37,5\%, aunque con importantes variaciones regionales (Sacristán, 2017). Además, este decreto, que se orienta a incrementar la parte privada de la financiación de los estudios, la que cubren las familias, introduce otra característica muy peculiar de nuestro sistema universitario (Sacristán, 2014), y es la de que los precios varían según el resultado, pues se empiezan a incrementar progresivamente a partir de la segunda matrícula.

En este contexto, de carreras más largas y costosas, y lejos de lo que en un principio cabría esperar, desde 2013 se vienen sucediendo distintos decretos y medidas que han dado un giro radical al sistema de becas haciendo de éste que quede muy mermada su función social y se priorice la eficiencia en el gasto. El sistema hace depender en mayor medida la obtención de las ayudas así como la cantidad de éstas de los logros académicos, por lo que pasa a ser de carácter competitivo (Río-Ruiz et al., 2015). Recordemos los principales cambios: se aumenta el requisito académico ${ }^{2}$ para obtener la matrícula gratuita exigiendo más del aprobado en secundaria, que es lo que se requiere al resto de estudiantes para entrar en la Universidad; se endurecen las exigencias académicas para acceder y mantener la beca universitaria, aún más si se opta a ayudas ligadas a renta y residencia y no sólo a la exención de matrícula; se incluye como novedad la necesidad de devolver el importe de la beca si no se supera el 50\% de los créditos matriculados; se introducen además condiciones variables en el componente compensatorio que dependerán de los resultados del solicitante y de los demás solicitantes así como del presupuesto anualmente destinado; lo que como consecuencia retrasa la adjudicación definitiva de las becas. El proceso de asignación de las

2 Para este curso se ha eliminado este requisito y sólo se exige el 5 para aquellos alumnos de nuevo ingreso que aspiren a beca de matrícula. Para obtener el resto de cuantías se sigue pidiendo el 6,5 . 
ayudas, además, y esta es otra novedad del nuevo «eficiente» modelo, al priorizar que el gasto público quede restringido a lo inicialmente presupuestado (lo que todos estos años no ha hecho sino decrecer) se hace no sólo competitivo, sino en cualquier caso más complejo e incierto para el becario. Asistimos, pues, a un giro «eficientista» que margina la finalidad igualadora de oportunidades que se espera de un sistema de becas, por lo que éste se desvirtúa inequitativamente al aumentar las exigencias para estar en la universidad precisamente a los que más dificultades tienen para acceder y permanecer en ella. No olvidemos, por otra parte, que las nuevas reglas ocasionan una disminución de la cuantía de las becas un $20 \%$, aún mayor, de un 49,5\%, para los perceptores de menor capacidad económica, los de umbral 1 de renta, resultante de haberse incrementado el número de becarios, a resultas de la crisis, disminuyendo a la vez en un 11,1\% el importe del presupuesto destinado a becas (Hernández Armenteros y Pérez García, 2017).

En este marco, de sucesivas reformas orientadas a hacer depender más del logro (tanto en las becas como en las tasas) y la renta (pues los estudios se alargan y sus precios suben mucho, mientras menguan las becas) la realización de estudios universitarios, he pretendido acercarme con la investigación que ahora presentaré al punto de vista del estudiante supuestamente más afectado, el de origen social bajo o mediobajo. Con ella se ha intentado reconstruir a través de la narración de las experiencias de este tipo de universitarios los sentidos que les confieren a las becas en el marco de sus apuestas educativas. Este abordaje se ubica así en lo que se ha dado en llamar la dimensión social de la educación superior, que, con todas estas modificaciones institucionales, acaecidas además en una situación de profunda crisis económica, cobra actualmente especial prioridad (Berlanga et al., 2018).

\section{Objetivos y metodología}

Esta aportación se basa, en efecto, en los resultados de una investigación realizada en el marco del proyecto «Los estudiantes de clases populares en la Universidad de Jaén frente a la universidad de la crisis» ${ }^{3}$. Se trata de un trabajo apoyado en entrevistas que han tenido lugar en el curso 2015-16 entre estudiantes de clases populares de la UJA. En las clases populares se han incluido tanto a los obreros de distintos sectores como a los autónomos manuales. Todos ellos tienen más bajas tasas de escolarización postobligatoria que las clases medias no manuales con capital educativo y que las clases altas (Martínez, J. S. y Fernández- Mellizo, M., 2016). En concreto la muestra la han compuesto: 14 estudiantes de clase obrera rural, 5 estudiantes de clase obrera de Jaén capital, 8 hijos de autónomos manuales, de pueblos de Jaén, y cuatro estudiantes de clase media que hemos utilizado como casos de contraste. Todos los estudiantes de clases populares han sido becarios, 15 de ellos sin interrupción y 12 intermitentemente ${ }^{4}$. En todos los casos se trataba de jóvenes, chicos y chicas en similar proporción (16 universitarias y 15 universitarios), representativos de la oferta de estudios de la UJA (10 estudiantes de algún grado de Ciencias Sociales, 8 de Humanidades o Educación, 7 de alguna Ingeniería, 4 de Ciencias, y 2 de Ciencias de la Salud). Con las variables sexo y tipo de estudio lo que he buscado es una distribución de la muestra en que no quedara sobrerepresentado ningún tipo de estudiante; además, me he valido de estos datos para poner en contexto las citas discursivas que obviamente aparecen anonimizadas. No obstante, la categoría central en el diseño muestral ha sido, como cabría esperar, la posición de clase, por lo que se ha buscado la saturación de los discursos enfatizando especialmente esta dimensión.

\footnotetext{
3 El trabajo se sitúa en el marco del proyecto UJA2014/06/33 subvencionado por la Universidad de Jaén y la fundación Caja Rural de Jaén (RFC/Acción6_2014).

4 Con becarios intermitentes quiero expresar que en alguno de los años de carrera se ha perdido la condición de becario, habiendo podido recuperar la beca algunos entrevistados y habiéndolo todos al menos estado intentando.
} 
En cuanto al contenido de las entrevistas, se pretendía el acercamiento a las experiencias de estos jóvenes tanto en su vertiente más académica (por qué estudian en la universidad, trabajo académico, preocupación por las notas, organización del tiempo, el precio de las matrículas, previsión de finalización de estudios, y planes de futuro), como social o relativa a las condiciones de vida (de qué viven, dónde viven, si trabajan o no y por qué, el sentido que les dan a las becas, dependencia de los padres).

El tema de las becas no es el que más ha centrado los discursos de los estudiantes. En algunos casos fue así, pero querría dejar constancia de que no ha sido ésta la tónica general de las entrevistas. Además, insisto en que con la entrevista lo que se pretendía era acercarse a los marcos de sentido desde los que los propios estudiantes habían conformado sus decisiones y hecho razonables sus prácticas y experiencias en la universidad. Por tanto, la entrevista no se estructuró muy directamente en torno al tema de las becas, sino que más bien se fue dejando a los entrevistados que dieran forma a su discurso, a partir de una alusión general a los modos de financiación de sus carreras con los gastos que conllevan. De hecho el carácter más abierto de las entrevistas muestra su lado más fecundo cuando los decires se despliegan sobre cuestiones pragmáticas (Alonso, 1994) o sea, cuando hablan de sus praxis en este caso como estudiantes universitarios. He avanzado alguno de los resultados de este análisis, sobre el sentido de las becas en la realización de estudios universitarios y las constricciones de las reglas del nuevo sistema (Langa Rosado, op. cit.), aunque no será esto lo que nucleará el contenido de este artículo.

Lógicamente los profundos cambios acontecidos desde el 2013 están también presentes, aunque aquí he de reconocer que he sido más directiva al preguntar a los universitarios su opinión sobre estas reformas, lo que nos revela, más adelante veremos, que no se es siempre muy consciente de ellas, y aún menos en la clave crítica que cabría esperar. Intentaré analizar lo sintomático de este rasgo discursivo. Este es, no obstante, el nivel en el que me centraré en este artículo; me moveré principalmente en el plano de las representaciones ideológicas sobre las becas y ayudas a los estudios: qué piensan sobre las nuevas condiciones (hasta qué punto son conscientes de los cambios, qué sentido les ven, cómo los valoran). Esto lo intentaré conectar con el sentido de la equidad educativa que manejan los estudiantes. Como sostiene Martínez García (2017), el contenido de lo que se entiende por equidad, de a qué grupos o categorías hay que beneficiar en el reparto de la tarta educativa y de qué manera, no es una cuestión universal sino que depende de opciones en última instancia éticas. Intentaré identificar cuál es el sentido de la equidad en los estudios universitarios que expresan nuestros entrevistados, así como el papel que entienden cumplen los sistemas de becas y ayudas al estudio. Pasemos, pues, a los resultados.

\section{Comprensivos con las razones de las reformas}

Acabamos de ver que las que transformaciones acaecidas a partir de 2013 han reforzado la condicionalidad de los criterios académicos, en clave además competitiva. Tengamos en cuenta que el perfil de los estudiantes de clases populares se caracteriza, entre otras cosas, porque viven sus apuestas educativas con una mayor dependencia del logro, dado que tienen menos naturalizada la opción universitaria (Reay, David y Ball, 2005; Langa y David, 2006). Es obvio que las nuevas exigencias se viven en forma de renovadas presiones y contradicciones (Río-Ruiz et al., 2014, 2015; Langa Rosado, 2018). No obstante, y curiosamente, muchos de nuestros informantes becarios, lejos de valorar estas reformas críticamente, tienden a intentar comprender las razones que justificarían las mayores exigencias. En la mayoría de los casos hacen todo un ejercicio de justificación de las causas que hay detrás de unos cambios que parecen haber asumido más bien contemplativamente. El siguiente fragmento resulta muy ilustrativo de este 
tipo de disposición: se relaciona la mayor dependencia de las ayudas de los resultados con la escasez de presupuestos, lo que justificaría un sistema competitivo pero supuestamente más meritocrático. Nótese, no obstante, cómo en la siguiente cita no se tiene conciencia que la competencia no está basada en las necesidades económicas, sino en los resultados, como si en un ejercicio de idealización se quisiera atribuir a la reforma un giro de mayor justicia social.

«En el segundo de carrera sí es verdad que me soltaron de golpe y porrazo abi toda la cantidad tres mil y pico euros... a partir de tercero si que me cambió el sistema, es verdad ahora lo digo, cambió, porque al principio te daban mil quinientos euros y entonces habia como tres fases. Una fase en la que todo el mundo recibia sus mil quinientos euros en la segunda fase el dinero que babia quedado entre los que más lo necesitaban se repartian otros mil quinientos euros y otra tercera fase en lo que ya lo que quedaba se repartía un poco también quién más lo necesitaba todavía. Entonces, ese modelo de repartir el dinero asi si que me pareció mucho más correcto que el que me bicieron a mi en segundo porque te implica... que no lo gastes todo, como digo yo que no lo fundas... porque yo conozco de casos de que cogían los tres mil euros y hacian... desde fiestas, coche, motos... despilfarrarlos o sea el dinero de las becas no iba para las becas». (M, varón, Historia).

La escasez presupuestaria en una situación de crisis parece ser un muy recurrente argumento justificador del incremento de exigencias. Estas además se entienden sin fisuras como una apuesta en favor de un sistema más meritocrático. Veamos en este sentido la siguiente argumentación que de nuevo añade a la razón del ahorro presupuestario, la del mayor control de supuestos casos de picaresca.

«Lo de las becas es que es... digamos una lotería. Que costara echar la beca quinientos euros y si después es verdad que te devolvieran los quinientos euros y la beca y si no te costara quinientos euros yo creo que la mitad de la gente no la echaría. Es lo mismo que el paro y lo mismo que pasa con todo, es que es la cultura de... de ir a pillar. De... de los picaros, de la picaresca». (C, varón, GAP (Gestión y Administración Pública).

«En algunas cosas si hombre... lo del seis y medio... tampoco lo veo bien pero bueno yo... la crisis que tenemos... también hay que verlo. Que... que el Estado es un hucha y si no metemos lo que no podemos es estar esperando a sacar, sacar, sacar. Yo eso también lo entiendo. Y lo del seis y medio pues hombre te mete presión pero está también lo de que si las apruebas todas no necesitas nota... yo eso dentro de lo que cabe no lo veo mals. (C, varón, GAP).

Hemos visto bastante más connivencia con el cambio hacia la competencia por resultados incluso entre estudiantes que pronto dejaron de ser becarios por su «fracaso» académico. Este joven sí se queja en cambio de las subidas de los precios de matrícula. De cualquier modo, nos sirve la cita para poner de manifiesto cómo los estudiantes lógicamente viven con claridad la conexión de las nuevas condiciones de las becas con la elevación de los precios y tasas de matrícula, y especialmente su incremento según el resultado.

«¿El tema de las becas? Por una parte veo que están bien porque se merece becas la gente que se esfuerza. Gente que no se esfuerza como yo no merece dinero. Yo pienso eso. Ahora... tener que pagar mil quinientos, dos mil euros de matricula también lo veo un poco excesivo. Si pusiesen un límite de novecientos, mil euros...novecientos, mil euros, mil... aunque tengas terceras matriculas cuartas matrículas pues lo verían un poco mejor». (A, varón, Ingeniería Mecánica). 
Luego hay casos en que la reforma les ha beneficiado, y se muestran muy «agradecidos», lo que nos informa también de la débil adhesión a la concepción de las becas como un derecho para igualar oportunidades, y en cambio su más clara vinculación a los méritos que justificarían las ayudas.

"Como ya estaba emancipado yo si me daban, ya si que me empezaban a dar mi beca. Y muy bien vamos la beca. Porque el primer año me pagaban solamente la matrícula y el segundo año me pagaron la matrícula y me dieron además setecientos euros. Que yo cuando los vi me quede...vamos, súper agradecido. Porque como cambiaron el tema del decreto de becas y ahora parece ser que también pagan por el tema del expediente pues... yo súper contento». (J, varón, Psicopedagogía).

\section{El estereotipo del becario fraudulento y/o que despilfarra}

Nos han sorprendido las recurrentes referencias a la existencia de becarios que despilfarran en el uso de las becas o que acceden a ellas fraudulentamente. En buena parte de los casos el énfasis en este tipo de prácticas responde a una presentación de sí mismo como becario honesto y que hace un uso productivo de las ayudas recibidas.

«Pero tampoco unos becorros que dan que... Que eso te da el dinero, vamos que tienes luego para hacerte una casa». (C, mujer, Ciencias Ambientales).

Veamos el caso de J. que primero relata lo que le ocurrió a un amigo que hubo de abandonar los estudios ante las nuevas condiciones

«Mi compañero de piso se tuvo que ir de casa, se vino a vivir con nosotros. Vino en busca de trabajo. Estuvo aqui unos meses. No encontró nada y al final se ha vuelto a Úbeda y el pobre... es que me da mucha rabia porque él estaba estudiando ADE (Administración y Dirección de Empresas) y fue justo ese año, fue... no sé si te acuerdas que cambió... las becas, pero en agosto, o sea en junio, julio o en agosto salió el BOE y ya te cambiaban totalmente las becas que fue cuando empezaron con el sesenta y cinco por ciento para los ingenieros, el ochenta y el noventa... Total que se lo follaron vivo. Porque le quedaba un examen que era el más chungo y tenía que aprobarlo si quería optar a la beca pero claro ya no le daba la nota media. Entonces de todas formas se bizo abi una vorágine, estalló la patata, no estudió suspendió, se volvió a Úbeda a hacer un grado superior».J, varón, Ingeniería Mecánica Eléctrica).

Pero luego este mismo estudiante se muestra así de contundente a la hora de justificar la reforma de las becas: un sistema más exigente en cuanto a resultados cribaría tanto a los perezosos, como, y aquí se desliza el argumento de los talentos naturales, a aquellos que no son «aptos para estudiar».

"Cuando yo empecé a estudiar la becas eran... una tontería ¿Sabes? Es que era... estaba muy muy mal. O sea igual de difíciles ahora antes era demasiado fácil. Yo conocía a un muchacho que me... estaba examinándome en junio cuando antes todavía habia septiembre. No fue en septiembre perdón. Y no lo habia visto en todo el año. Y digo: "Ostia tío ¿Tu dónde estudias?". Y dice: "Yo electricidad". Digo: "No te he visto nunca" y dice: "Ya. Es que no he venido". Y digo "¿Y qué haces aquí?". Y me dice: "Nada, que para no tener que devolver la beca tengo que presentarme a tres asignaturas". Me quedo así y digo: "¿Entonces qué has venido al examen...? Y dice: "Sí, sí me presento y me voy". Y digo: "¿Y cuánto te han dado de beca?". Y dice: "Seis mil pavos". Y digo: "¿Y qué has hecho?". O sea, ya con el cachondeo le dices: "¿Y qué has hecho, no? Y dice: "Pues hincharme a fiestas". Entonces claro, eso con dieciocho años dices: "Ostia que cabrón no sé qué...". Ya con la edad lo que dices es: "Tú lo que eres es un bijo de puta" ¿Vale? Entonces si veo bien que se haya vuelto más estricto, lo veo 
bien. Vamos a ver es que a ti te den seis mil euros y que tu sin motivo real no apruebes el cincuenta por ciento de los créditos matriculados es... es pereza. Es que es... seamos realistas, es de no trabajar. Vamos a ver, el cincuenta por ciento para no tener que devolverla. Que si no eres apto para estudiar lo que estás estudiando... Buf... Hay gente que no es apto. Por desgracia es verdad que bay gente que se mete en la carrera que estudia, que estudia... Hay gente que no puede. No tira para delante porque no puede. Es una lástima pero es real, la mayor parte no, o sea en esa carrera no bay ningún tonto... Pero está bien que se hayan encrudecido un poco y que sea difícil para que la gente no ande con tanto mamoneo». (J, varón, Ingeniería Mecánica Eléctrica).

Similar en su expresión ambivalente la valoración de este otro chico, exbecario, pero igualmente escorada hacia una gran interés por ser «comprensivo» con la necesidad de la reforma de las becas y las supuestas virtudes del nuevo sistema.

"Que den becas a gente sin recursos, que no se lo pueda permitir en exceso, estudiar y de verdad quieran
estudiar, yo lo veo magnifico. Ahora el cómo se imparten las becas, sobre todo antes que mi madre me
contaba que antes la gente se metía a estudiar una carrera y luego no iba porque sólo quería el dinero
de la beca, eso sí me parece mal. Porque te estás aprovechando del sistema para luego no estudiar.
Ahora los cambios que hicieron a las becas hace poco yo creo que eso se debería ver más porque hay
casos que a lo mejor muchos de que hay gente que de verdad que lo necesitaba y que para estudiar
dependía exclusivamente de eso y twieron que dejar de estudiar o seguir de una manera muy dificul-
tosa porque no podían. No sé por qué exactamente. A lo mejor le han quedado una o dos. Porque
todos podemos tener un mal año. Eso puede pasar y de hecho fue a mi lo que me pasó». (P, varón,
Telecomunicaciones).

Al contrario de lo que podíamos haber esperado, han sido más bien excepcionales los discursos críticos y fundamentados en torno a qué sentido tienen los cambios normativos que regulan la consecución y mantenimiento de becas y ayudas. Veamos uno de los más sólidamente argumentados, si bien quizá sea interesante el detalle de que se trata de un estudiante de Magisterio, que por ello exhibe con cierta solvencia el discurso de la equidad. Trae en primer lugar a colación el ejemplo de un compañero que tuvo que devolver el dinero de la beca y por ello ponerse a trabajar, con el resultado de haber tenido que abandonar los estudios.

«Yo creo que genera desigualdad porque si a... todo el mundo puede tener un mal año, o todo el mundo no tiene la misma capacidad... yo estoy de acuerdo en que se exija un minimo... estoy de acuerdo en que se exija a lo mejor un mínimo porque en verdad el dinero es de todos y tenemos que ser conscientes de que, de que es un bien que tenemos que aprovechar pero también considero que, por ejemplo, que para cobrar una beca te pongan una nota de un siete o de un seis y medio, en los master me parece que es un siete de media tienes que tener para cobrar, y en la carrera de grado un seis y medio; o en el caso de mi compañero que no le salió bien la aventura, o no ha podido seguir porque a lo mejor si a él no le piden el reintegro de la beca, él a lo mejor se bubiera intentado hacer el esfuerzo con el trabajo y demás y seguir en la carrera, si no se matricula de diez se matricula de cuatro, pero lo va sacando poco a poco; lo que ha provocado que encima tiene que devolver el dinero, tiene que pagar a hacienda lo que le debe y como no page encima a hacienda tiene que pagar los intereses, y encima pues tendrá que ver...tiene que dedicarse a su trabajo, es imposible que aunque quiera seguir pueda seguir, es que cuando tenga que devolver la beca, pagar una matrícula en la universidady su trabajo, es imposible». (M, varón, Primaria).

Aun así M. reproduce de nuevo el estereotipo del becario fraudulento, en este caso el tan extendido de los «becarios 6.000», aunque lo que propone para ello es un sistema de mayor control de los posibles 
casos de fraude. Concluye criticando el descenso en las cantidades percibidas, y se trata además de un discurso muy lúcido y expresivo que concuerda con los datos que realmente muestran esta tendencia, como veíamos al principio.

«Y en los pueblo pequeños yo creo que lo del fraude se ve más todavía, porque tú ves gente que... observas la casa. Observas la casa y observas el campo que tiene. Y luego resulta que las famosas Becas Seis Mil que se dan en los ciclos y bachillerato, que esa gente se lleva esas becas y tú dices: "bueno, ¿y tú vives en una casa de cuatro plantas?" y teniendo parcelas de dos mil quinientos olivos ¿Cómo pueden cobrar una beca seis mil?

Yo defiendo las becas, lo que no defiendo es el control que hay de las becas a lo mejor. Yo pienso que lo que han hecho no ha sido controlar más las becas sino pincharle más al que menos tiene, ahora mismo. Y no controlar a lo mejor quién engaña o quien despilfarra la beca de verdad. Porque bueno a ti te dan el dinero y tú eres responsable, el Estado ha cumplido por ti, te ha dado tu dinero y tú ahora eres responsable de en qué te lo gastas, eso ya es una cosa aparte. Pero por ejemplo otro compañero que tengo, él tiene un piso, su abuela tiene un piso aquí y en la beca a puesto que la abuela le ha alquilado el piso a no sé... o que... o el piso se lo ha dado al tío, el tío le ha alquilado el piso a élpara cobrar la beca. Y él no paga nada de alquilé. Y ha cobrado la beca con la parte de alquiler del piso, y en verdad no paga alquilé. Y todas esas cosas pues a lo mejor no están controladas. O como el que pone que está viviendo en un piso y en verdad está viviendo en su pueblo. Y no está pagando alquiler. Y esas cosas no se revisan, pienso. Entonces lo único que han hecho con subir los requisitos de nota y forzar más la renta para que las becas sean más bajas y demás, porque lo de la parte variable como le he dicho yo creo que es un engaño para quitarnos un poco más de la beca... un poco más no, casi dos mil euros de beca a los que a lo mejor cobrábamos antes más, pues pienso que se han metido con esas cosas y no se han esforzado tanto en buscar el fraude que de verdad hay a lo mejor hay en el sistema de becas. Que es donde se deberian a lo mejor haber centrado. Es mi opinión». (M, varón, Primaria).

Está muy extendido en general, a pesar de estas excepciones de crítica expresa y argumentada, un cierto discurso barnizado de un tono moralizante meritocrático que dificulta la explicitación de los factores estructurales de la desigualdad social que intervienen en lo educativo. No parece en general que se tenga mucha idea sobre la función de las becas en favor de igualar las oportunidades así como de su debilitamiento con los cambios recientes, tal como indica el último informe de la CRUE (2018) ${ }^{5}$. Es como si el discurso productivista se manifestara incluso aún más fuertemente entre estos estudiantes, que no se permiten distanciarse así del "mito meritocrático" (Río-Ruiz, 2014). De ahí la evidente tendencia a reproducir el estereotipo de los becarios que hacen mal uso de las ayudas, y que les sirve no solo para presentarse a sí mismos como «buenos becarios», sino como argumento que tiende a justificar las últimas transformaciones en el sistema.

\section{Las becas Erasmus como opción lejana y/o arriesgada}

Hasta ahora he estado describiendo una adhesión especialmente expresiva a las propuestas meritocráticas que parecen conferir legitimidad a la reforma: que los becarios respondan más académicamente dado que se trata de dinero público. No obstante, en nuestras entrevistas se ha dado la ocasión de que los estudiantes se expresen sobre otro tipo de becas, en concreto sobre las becas Erasmus. Cuando se han referido a

\footnotetext{
5 «La igualdad de oportunidades se conjuga mediante la aplicación de políticas que permitan superar la brecha económica que impide asumir libremente las decisiones educativas a los alumnos pertenecientes a familias más desfavorecidas en sus niveles de renta por no poder financiar los gastos directos, indirectos y de oportunidad que implica la prolongación de su desarrollo educativo. En consecuencia, la calificación académica no puede ser una exclusión para acceder y permanecer en los estudios universitarios con requisitos académicos diferentes a los que operan para los alumnos que no solicitan la condición de becario» (p. 38).
} 
ellas los entrevistados se han mostrado en la mayor parte de los casos descreídos, distantes pragmáticamente, como aludiendo a algo que no forma parte de sus opciones. Casi todos ellos entienden que es una oportunidad interesante y recomendable, pero también la mayoría la percibe lejana a sus posibilidades reales, tanto por la escasa cobertura, que obligaría a las familias a hacer aún un mayor esfuerzo financiero, como por el problema añadido del idioma, que es todo un hándicap para muchos de estos chicos. Fijémonos en lo curioso y sobre todo muy revelador de la siguiente cita, en que se apunta a la ausencia de la «beca física», de dinero efectivamente disponible para gastarlo en el extranjero.

"Y sobre todo de amigos más mayores que se habian ido de Erasmus. Habia muchos problemas luego a la hora de que te ingresaban los... la beca, de que los pagos, que venian más tarde, y mis padres no me podían costear a lo mejor una vivienda en Alemania todos los meses sin beca, sin beca física, o sea el... el no saber cuándo te va a venir el dinero». (P, varón, Biología).

Muchos descartan las becas Erasmus por motivos económicos, por la dificultad del idioma y/o por el miedo a lo desconocido.

"Probablemente pero yo tengo otros compañeros que lo han hecho y me han dicho que han necesitado ayuda de sus padres y entonces... comprometer un poco más la situación de mi casa como que no era plan la verdad. Entonces nunca llegué a decirle: "quiero irme de Erasmus". Sabia, también era consciente de cómo estaban las cosas en mi casa». (M, varón, Historia).

«El idioma porque ya era de por sí... salir adelante sin beca y sin nada, no me voy a ir a una Erasmus, aunque supuestamente para la Erasmus te dan becas pero si ya me costaba también alguna asignatura hablando español, si yo me voy fuera a donde sea buf... ya me pierdo por completo. Es más dicen que la Erasmus no, no tiene buena pinta en el sentido de que la gente se va de Erasmus, la mayoría, a, pues a ver mundo y que la carrera va aparcada y, eso bace falta que encima pierda un año entero de la carrera; tendría que echar otro año y...». (E, mujer, Derecho).

"Como te he dicho antes es que soy muy casero. Me da miedo ir por abi. La verdad es que sí. Soy ... ya aparte del tema económico fuera, yo sé que si decido de irme de Erasmus, gracias a dios en mi familia no falta el dinero mis padres me lo van a pagar aparte de las ayudas, las becas y demás pero... no he ido porque no he querido. Porque ya le digo, me da miedo salir fuera. El típico destino a Italia o a Portugal, fijate Portugal que cerquita está que no... No he ido porque no he querido ir yo». (J, varón, Administración y Dirección de Empresas).

Hay quien además señala problemas importantes de falta de información por descoordinación y mala gestión.

«Sí, ahora tengo una Erasmus el año que viene para Lisboa, lo tengo concedido pero no tengo ni idea de si me voy a poder ir o no porque está tan mal gestionado que bueno...

(...) Te pierdes, te pierdes muchas cosas, te pierdes muchisimas cosas, y la verdad que es muy... y es, ya te digo, el noventa por ciento de los Erasmus que se han concedido en mi clase se van o se han rechazado ya... de hecho tuve que rechazar uno en la primera convocatoria porque está muy mal gestionado...». (J, varón, Educador Social).

Incluso se aprecia en la consideración de la posibilidad de disfrutar de estas ayudas un claro efecto del sistema competitivo de las becas generales del Ministerio. Irse de Erasmus es aquí valorado como 
una opción arriesgada, pues puede bajarte el expediente, con repercusión en la cuantía de la beca que se percibirá.

«A ver. Lo de las Becas Erasmus sinceramente creo que es una farsa. Es una farsa porque yo be estado hablando con profesores y nos dicen: "Mira, a nosotros nos están llegando Erasmus que no tienen ni idea y los tenemos que aprobar porque nos da vergüenza mandarlos a su país con las asignaturas suspensas". Claro. Yo me voy a un país con un B1 de inglés, que sinceramente creo que no es nada para irte a Polonia. Con un B1 de inglés no vas a saber nada. Entonces si tú intentas irte a otro país y tienes que mantener una media y no sabes relacionarte digamos con las personas de ese país o con el idioma o con las clases esa media va a descender. Y si va a descender la media no vas a tener acceso a beca el año siguiente. O sea que es una forma digamos de encauzar la educación permitiéndote conocer Europa pero es un falso... un falso amigo. En verdad no te está beneficiando para nada». (R, varón, Trabajo Social).

Las becas Erasmus, pues, nos han servido de ocasión para contrastar por un lado las expresiones más moralistas e idealizantes que se despliegan en torno a las becas ordinarias, con, por otro lado, las más alejadas de este sesgo de deseabilidad social, en el caso de las famosas becas de movilidad internacional. Quizá se permitan distanciarse más del tono de la corrección política al hablar sobre estas ayudas porque las entienden como un recurso que no está muy al alcance de sus posibilidades. En cualquier caso, el contraste de nuevo remite al despliegue ideológico del discurso de la meritocracia y sus bondades con el que estamos viendo tienden a valorar el aumento de las exigencias académicas en el nuevo sistema general de becas y ayudas al estudio.

\section{Discusión de resultados. El desfase entre los «decires» y los «haceres»}

Buscábamos con las entrevistas acercarnos a los marcos de sentido desde los que los estudiantes configuran sus decisiones y dan sentido a sus experiencias en la universidad. Aunque los cambios acontecidos desde el 2013 en el sistema de concesión y mantenimiento de las becas estuvieron presentes, no siempre expresaron ser muy conscientes del sentido de estas transformaciones y desde luego no en la clave crítica que podríamos haber esperado. Esto se ha leído como un síntoma de la endeble concepción que se tiene del papel que el sistema de becas y ayudas al estudio juega en la igualación de las oportunidades de quienes tienen distintas posiciones de clase social.

Muy diferente, no obstante, lo que nos ha mostrado la faceta más pragmática de los discursos, o sea, cuando los estudiantes nos hablan de lo que hacen con las becas. Aquí encontramos un relato donde se expresan con claridad las nuevas limitaciones que el sistema les genera. Aunque en este artículo no hemos entrado en la descripción de estas constricciones, recordemos alguna (Langa Rosado, op. cit.): la beca es la condición que posibilita la apuesta universitaria, que se entiende muy costosa y que supone, como dificultad añadida, depender por un tiempo prolongado de la familia. Las becas constituyen un modo de aminorar esta dependencia y el sentimiento de deuda a ella asociado, lo que hace que su consecución y mantenimiento se conviertan en asuntos de vital importancia a la hora de continuar estudiando. Con las nuevas condiciones, el colchón familiar se convierte en un necesario soporte frente a las contingencias e incertidumbres del sistema (becas insuficientes, concedidas tardíamente, cuyo importe se desconoce hasta el final de curso; o pérdida de becas con los nuevos criterios más sujetos al logro académico). No obstante, este soporte siempre se vive problemáticamente y a veces es hasta como imposibilidad para muchas familias que han visto muy empeorada su situación económica con la crisis. 
A pesar del enorme esfuerzo, tanto académico como económico que caracteriza a este colectivo y que en las entrevistas nos expresan con crudeza en forma de nuevas presiones, resulta paradójico lo persistentemente que se reproduce en sus discursos el estereotipo del becario despilfarrador/-a y/o fraudulento. Esto está en la base de un tono más bien connivente con importantes aspectos de la reforma, que apunta, además, a una sólida y acrítica adhesión al discurso de la meritocracia y sus virtudes. Una reforma, recordemos, que ha virado el sistema de becas hacia una mayor vinculación de la posibilidad de estar en la universidad al rendimiento del y de la estudiante (no sólo en las becas, también antes en los precios de matrícula) y que con ello ha redoblado la tradicional dependencia del logro que ya de por sí tienen los estudiantes de clase baja. En efecto, los estudiantes de clases populares tienden a dar mayor cuenta de los resultados académicos, lo que se concreta tanto en sus elecciones iniciales como a lo largo de la carrera (Langa y Río-Ruiz, 2013; Troiano, Torrents y Sánchez Gelabert, 2017).

Para ir concluyendo, he querido enfatizar este desfase entre los «decires» y los «haceres» (Martín Criado, 1998), entre las representaciones en torno a las becas y los discursos más pragmáticos (sobre lo que se hace o se deja de hacer con/por las becas). Y ello porque he interpretado esta aparente disparidad como un síntoma de una representación ideológica cada vez más privatista de la educación, un debilitamiento de la concepción de ésta como derecho ciudadano, y sí en cambio como un bien dependiente de los méritos/talentos personales, pero no olvidemos que en su defecto, aunque éste parece no ser un aspecto muy explícito en los discursos, también del capital económico ${ }^{6}$ que se posea. Quienes se ven más afectados por una reforma «eficientista», aquellos que viven las nuevas y redobladas exigencias en forma de mayores obstáculos e incluso contradicciones, expresando cierta connivencia con los cambios que les hacen más complicadas sus apuestas universitarias. Manifestaciones supuestamente paradójicas que nos revelan un concepto de equidad bastante endeble: se ignora o se margina lo que tiene que ver con el peso de la clase social en la educación y en ese sentido se tienden a desconocer los mecanismos por los que las becas pueden actuar, en distinto grado, igualando oportunidades.

\section{Referencias bibliográficas}

Alonso, Luis Enrique (1994): "Sujeto y discurso: El lugar de la entrevista abierta en las prácticas de la sociología cualitativa” en José Manuel Delgado y Juan Gutiérrez Fernández (comp.): Métodos y técnicas cualitativas de investigación en ciencias sociales. Madrid: Síntesis.

Berlanga Silvente, Vanesa; Figuera Gazo, Ma Pilar y Pons Fanals, Ernest (2018): "Modelo predictivo de per-sistencia universitaria: Alumnado con beca salario". Educación XX1, 21 (1), 209-230.

Hernández, Juan y Pérez, Jose Antonio (2017). La Universidad española en cifras, 2015/2016. CRUE Universidades españolas.

Hernández, Juan y Pérez, Jose Antonio (2018). La Universidad española en cifras, 2016/2017. CRUE Universidades españolas.

Langa Rosado, Delia (2018): “La apuesta universitaria en los jóvenes de clases populares. Entre la promoción social y la falta de horizonte”. RES, 27 (1),137-145.

Langa-Rosado, Delia y David, Miriam (2006): “A 'Massive University or a University for the Masses’: Continuity and Change in Higher Education in Spain and England". Journal of Education Policy, 21 (3), 343-365.

6 ¿Quizá habría que ir añadiendo también el capital político? 
Langa-Rosado, Delia y Río, Manuel Ángel (2013): “Los estudiantes de clases populares en la universidad y frente a la universidad de la crisis: persistencia y nuevas condiciones para la multiplicación de la desigualdad de oportunidades educativas". Tempora, 16, 71-96.

Martín Criado, Enrique (1998): “Los decires y los haceres”. Papers, 57, 57-71.

Martínez García, José Saturnino (2017). La equidad y la educación. Madrid: Catarata.

Martínez, José Saturnino y Fernández- Mellizo, María (2016): "Inequality of Educational Opportunities: School Failure Trends in Spain (1977-2012)". International Studies in Sociology of Education, 26 (3), 267-287.

Río-Ruiz, Manuel Ángel (2014): "Efectos de la conversión en becario y consecuencias de la reforma del sistema de becas entre universitarios de clase obrera”. RASE, 7 (2), 468-487.

Río-Ruiz, Manuel Ángel, Jiménez-Rodrigo, M. Luisa y y Caro-Cabrera, Manuel Jesús (2015): “The Shifting Financial Aid System in Spanish University: Grant-Recipients'Experiencesand Strategies”. Critical Studies in Education, 56 (3), 332-350.

Reay, Diane; David, Miriam y Ball, Stephen (2005). Degrees of Choice: Social Class, Race and Gender in Higher Education. Stoke-on-Trent: Trentham Books.

Sacristán, Vera (2014). El cost d'estudiar a Europa. Preus, beques, préstecs i ajuts a les universitats europees (20132014). Barcelona: Observatory del Sistema Universitari.

Sacristán, Vera (2017). Qui finança la universitat? Comparació entre comunitats autònomes a Espanya, Europa $i$ l'OCDE, 2009-2015. Barcelona: Observatori del Sistema Universitari.

Troiano, Helena; Torrents, Dani; Sánchez-Gelabert, Albert y Daza, Lidia (2017): "Evolución del acceso a la universidad entre la población joven en Cataluña". Cuaderno de Relaciones Laborales, 35 (2), 281-303.

\section{Nota biográfica}

Delia Langa Rosado es es profesora titular de la Universidad de Jaén (España). Su principal interés investigador ha girado en torno a las desigualdades educativas, y especialmente en los estudios universitarios (https://entramadossociales.org/perfil/delia-langa-rosado/). Ha sido respectivamente vicedirectora y directora de la Revista de la Asociación de Sociología de la Educación (2012-2016). Ha realizado diversas estancias de investigación, destacando la del Instituto de Educación de Londres en 2010. Actualmente trabaja en un proyecto I+D sobre inclusividad en la Universidad (Proyecto EDU2017-82862-R). Identificación ORCID: https://orcid.org/0000-0002-7680-828X. 